\title{
Ressignificando a Relação entre Calouros e Veteranos: Mentoria de Pares na Visão de Alunos Mentores
}

\author{
Giving New Meaning to the Relationship Between Freshmen and \\ Seniors: Peer Mentoring in the View of Student Mentors
}

\section{PALAVRAS-CHAVE}

- Educação Médica.

- Mentores.

- Orientação.

- Estudantes de Medicina.
Marina Guitti de Souza ${ }^{I}$ (iD Lígia de Fátima Nóbrega Reato ${ }^{I}$ (D Patrícia Lacerda Bellodi ${ }^{I I}$ (D

\section{RESUMO}

Introdução: A mentoria de pares tem sido reconhecida como uma das intervenções de suporte para o enfrentamento de um dos mais estressantes momentos para os estudantes - a transição para o ensino superior. Este estudo traz a experiência do primeiro ano de atividade de um programa de mentoria de pares realizado numa escola médica brasileira. Este estudo teve como objetivos descrever o processo do "fazer mentoria de pares" com calouros do curso médico e apresentar as satisfações e os desafios encontrados no caminho, assim como as sugestões para o aprimoramento da atividade. Método: Analisaram-se qualitativamente os feedbacks enviados ao longo do ano por veteranos que assumiram o papel de mentores. Os depoimentos foram sintetizados tendo por referencial o método do discurso do sujeito coletivo. Resultados: Os mentores realizaram ações de suporte acadêmico e pessoal, e também foram anfitriões do ambiente acadêmico. Os encontros presenciais foram de difícil realização, sendo complementados por encontros virtuais. Encontrar um horário comum e manter a periodicidade dos encontros foram os principais desafios. Desinteresse de alguns calouros e esvaziamento de demandas na segunda metade do ano geraram frustração. No entanto, os mentores observaram o crescimento dos calouros e o seu próprio desenvolvimento pessoal, expressando sentimentos de gratidão e satisfação com os vínculos afetivos criados. Para as próximas experiências, os mentores sugeriram um início mais precoce do programa, menor número de calouros por grupo e maior acompanhamento das atividades pela coordenação. Pedidos expressos para que a mentoria continue no futuro foram feitos. Conclusóes: Fazer mentoria de pares é um fazer amplo nos campos acadêmico, pessoal e social. Os calouros recebem ajuda para lidar com as incertezas do início do curso em um espaço seguro em que ansiedades podem ser compartilhadas. A relação de mentoria é mutuamente benéfica e o veterano também se desenvolve ao longo do processo. Dificuldades na realização dos encontros mostraram-se presentes e aprimoramentos precisam ser realizados para maior engajamento com a atividade e ampliação de seus benefícios.

Faculdade de Medicina do ABC/Centro Universitário Saúde ABC, Santo André, São Paulo, Brasil.

${ }^{\mathrm{II}}$ Universidade de São Paulo, São Paulo, São Paulo, Brasil. 


\section{KEYWORDS}

- Medical Education.

- Mentors.

- Orientation.

- Medical Students.

Recebido em 24/4/20

Aceito em 16/10/20

\section{ABSTRACT}

Introduction: Peer mentoring has been recognized as one of the support interventions to face one of the most stressful moments for students - the transition to higher education. This study brings the experience of the first year of activity of a peer mentoring program carried out at a Brazilian medical school. This study aimed to describe the process of peer mentoring with freshmen on the medical course and present the reasons for satisfaction and challenges encountered along the way, as well as suggestions for improving the activity. Method: Qualitative analysis of feedback submitted over the year by seniors, in the role of mentors. The statements were summarized using the Discourse of the Collective Subject method. Results: The mentors performed actions of academic support, personal support and were also hosts of the academic environment. It proved difficult to hold face-to-face meetings, so they were complemented by virtual meetings. Finding a common schedule and maintaining the frequency of meetings were the main challenges. Lack of interest from some freshmen and drying up of demands in the second half of the year generated frustration. On the other hand, the mentors observed the growth of freshmen and their own personal development, expressing feelings of gratitude and satisfaction with the affective bonds created. For the next experiences, the mentors suggested an earlier start for the program, fewer freshmen per group and greater monitoring of the activities by the coordination. Express requests have been made for mentoring to continue in the future. Conclusions: Peer mentoring is a broad activity in the academic, personal and social fields. Freshmen are helped to deal with the uncertainties of starting the course in a safe space where anxieties can be shared. The mentoring relationship is mutually beneficial, and the senior also develops throughout the process. There were difficulties in holding the meetings and improvements are needed in order to engage more with the activity and expand its benefits.

\section{INTRODUÇÃO}

A transição para o ensino superior é um momento delicado para os jovens, não se tratando de uma continuidade e sim do enfrentamento de uma série de mudanças, sendo necessário assimilar novas regras e saberes complexos para entrar nessa nova cultura - a universitária. Esse processo envolve diversas rupturas simultâneas: nas condições de existência, na vida afetiva e nas regras de apropriação do saber ${ }^{1}$.

No Brasil $^{2-5}$, tal como em outros lugares do mundo ${ }^{6-9}$, a entrada na universidade e no curso médico gera muito estresse, e, passada a euforia pela conquista, surgem sentimentos de frustração e desencanto. $\mathrm{O}$ grande volume de novos conhecimentos, a deficiência na formação pedagógica dos professores, a necessidade de desenvolver novas formas de aprender e estudar e a pressão pelo desempenho são alguns dos desafios acadêmicos do calouro. Do ponto de vista pessoal, muitos deixam suas cidades e passam a assumir responsabilidades por tarefas cotidianas que concorrem com seu tempo para o estudo. No contexto social, a integração ao novo ambiente e aos colegas nem sempre é tranquila e acolhedora, com forte tradição de relações hierarquizadas entre os anos acadêmicos.

Coulon $^{1}$ diz que a principal tarefa do estudante, em especial no primeiro ano, é manter-se na universidade e, para isso, tem que aprender o “ofício de estudante". Segundo esse autor, é fundamental ajudar o calouro a se "afiliar" ao novo mundo em que está ingressando, isto é, ajudá-lo a se tornar membro desse novo grupo, o que implica compreender e interiorizar o mundo acadêmico da mesma maneira que os demais.

A mentoria, relação na qual uma pessoa mais experiente oferece apoio e orientação a um jovem no começo de sua jornada, pode ser uma das intervenções de suporte a esse momento de transição, ajudando na afiliação dos novos alunos ao universo social do ensino superior e do curso médico ${ }^{10}$. Tendo origem na relação de suporte e orientação estabelecida entre Mentor e Telêmaco, na Odisseia, de Homero, um mentor compartilha sua experiência e apoia o iniciante para que este desenvolva um sentimento de identidade e competência. O mentorado, por sua vez, expõe suas dúvidas e dificuldades, examinando e refletindo sobre seu desenvolvimento ${ }^{11,12}$. Se houver compromisso e investimento pessoal, a mentoria poderá favorecer o crescimento mútuo, numa relação de mão dupla ${ }^{13}$.

Como estratégia de suporte e desenvolvimento, a mentoria se disseminou em diferentes contextos. No cenário universitário ${ }^{14}$, a mentoria pode estar presente na forma clássica, estabelecida entre professores e alunos, individualmente ou em grupo, e também ocorrer entre pares (peer mentoring), isto é, entre alunos.

No campo da educação médica, a publicação de relatos de experiência e pesquisas sobre mentoria tem crescido vertiginosamente ${ }^{15,16}$. Programas de mentoria de pares, em especial, em que alunos que recentemente passaram por determinadas experiências ajudam nos problemas cotidianos enfrentados por colegas menos experientes, começam a ganhar também maior atenção.

A mentoria de pares está se popularizando em relação ao mentoring tradicional por duas razões principais: 1 . há maior facilidade de os estudantes expressarem seus sentimentos a seus pares e 2 . nos modelos tradicionais, os alunos tendem a corresponder às expectativas que acreditam existir dos mentores em relação a eles ${ }^{17}$. Na avaliação de alguns programas de mentoria tradicional, aparece a solicitação pelos mentorados de mentores com idades mais próximas das deles ${ }^{18}$, justificando que a relação se tornaria mais amigável e confortável entre os participantes, permitindo maior compreensão mútua ${ }^{19}$. Além disso, a mentoria de pares tem ganhado força ao facilitar a abordagem de assuntos considerados de grande importância pelos alunos, como a

REVISTA BRASILEIRA DE EDUCAÇÃO MÉDICA

2 44 (4) : e174; 2020 
saúde mental e o bem-estar ${ }^{20,21}$.

A mentoria de pares também tem sido reconhecida como uma das intervenções que podem ajudar no enfrentamento dos desafios de um dos mais estressantes períodos para os alunos - a transição para o ensino superior ${ }^{21}$. Entretanto, apesar de seus efeitos positivos, como o fortalecimento do vínculo entre colegas e a criação de espaços acolhedores para o compartilhamento de sentimentos e pensamentos, uma recente revisão do tema mostra uma escassez de estudos sobre a mentoria de pares na formação médica ${ }^{22}$.

Este estudo traz a experiência do primeiro ano de atividade de um programa de mentoria de pares realizado numa escola médica brasileira. Por meio dos feedbacks enviados por veteranos, no papel de mentores, temos como objetivo descrever o processo do "fazer mentoria de pares" na chegada dos novos alunos ao curso médico. Em especial, exploramos e discutimos as satisfações e os desafios encontrados pelos mentores ao longo do caminho, assim como suas sugestões para o aprimoramento da atividade.

\section{MÉTODOS}

O Projeto $\mathrm{ABC}$

Considerando a necessidade de suporte e orientação dos novos alunos na transição para o curso médico, alunos do Diretório Acadêmico da Faculdade de Medicina do ABC (FMABC) criaram, no final de 2016, o Projeto $\mathrm{ABC}$, um programa de mentoria entre pares.

No Projeto $\mathrm{ABC}$, a mentoria ocorre entre um aluno do segundo ano da graduação (mentor) e um calouro do primeiro ano (mentorado) com o propósito de trocar experiências sobre a "nova condição de estudante de Medicina”. Foi estruturado como um programa de participação voluntária com um mentor para grupos de cinco a dez mentorados.

Depois da divulgação do propósito do programa, os coordenadores do projeto realizaram entrevistas de seleção com os alunos do segundo ano interessados em serem mentores. Valorizaram-se as seguintes competências no perfil dos futuros mentores: compreensão dos objetivos do projeto e de seu propósito para além da área acadêmica, incluindo o desenvolvimento pessoal, disponibilidade para realizar as atividades propostas e comprometimento com o programa por um ano. Buscou-se compor o grupo de mentores contemplando alunos que participassem das mais diversas atividades acadêmicas e extracurriculares no campus universitário. Ao todo foram selecionados 24 mentores de um total de 42 inscritos.

Cada mentor aprovado teve como tarefa realizar uma descrição de si mesmo, e seus perfis foram divulgados para os 130 alunos ingressantes em 2017. Destes, 90 optaram, voluntariamente, por participar da atividade e puderam escolher três opções de mentores. Os grupos foram compostos buscando corresponder às preferências apontadas pelos calouros. Cada mentor recebeu, em média, cinco mentorados.

Foi proposto que os grupos realizassem encontros presenciais mensais e não havia temas-chave para os encontros. A duração estabelecida para a primeira edição programa foi de oito meses, tendo iniciado em março de 2017.

\section{Participantes}

No primeiro ano do projeto, 24 alunos participaram como mentores. A grande maioria (80\%) era do sexo feminino, refletindo a composição da turma de alunos do segundo ano acadêmico do curso de Medicina em 2017. A faixa etária variou de 18 a 24 anos.

\section{Coleta dos dados}

Os mentores foram estimulados a enviar relatos de suas experiências à coordenação do programa ao longo do ano. Esses relatos eram não estruturados, buscando, nesse primeiro ano do programa, aproximações livres e espontâneas sobre a dinâmica e o conteúdo dos encontros realizados. Foi disponibilizado um canal de comunicação on-line durante todo o ano, para o seu envio.

\section{Análise dos dados}

O material obtido foi submetido à análise temática de conteúdo ${ }^{23}$, com o objetivo de descobrir os núcleos de sentido presentes nos relatos. Numa primeira fase, por meio de leitura flutuante, realizada de forma independente pelas autoras, fez-se a pré-exploração do material, seguida então da formulação das categorias de análise, num processo contínuo de categorização e subcategorização.

A validação das categorias ocorreu por meio de discussão pelo grupo de pesquisa que, por consenso, buscou estabelecer aquelas que melhor retratassem as experiências descritas.-

\section{RESULTADOS}

Respondentes

Dos 24 de mentores do programa, 22 mentores (92\%) enviaram relatos sobre os encontros, num total de 41 relatos ao longo do ano. Em média, cada mentor enviou dois relatos sobre sua experiência ao longo do ano. Os relatos não correspondiam a cada encontro realizado pelos mentores, sendo, em sua maioria, uma síntese livre e geral sobre a experiência vivenciada até aquele momento.

\section{Temas e subtemas}

Os relatos foram categorizados nos seguintes grandes temas:

1. O que se fez.

2. Como se fez.

3. Dificuldades no fazer.

4. Satisfações com o fazer.

5. Benefícios do fazer.

6. Sugestões para o fazer.

Cada tema foi subdividido em subtemas que apresentamos na Figura 1. Os discursos ilustrativos das experiências dos grupos são apresentados a seguir. 


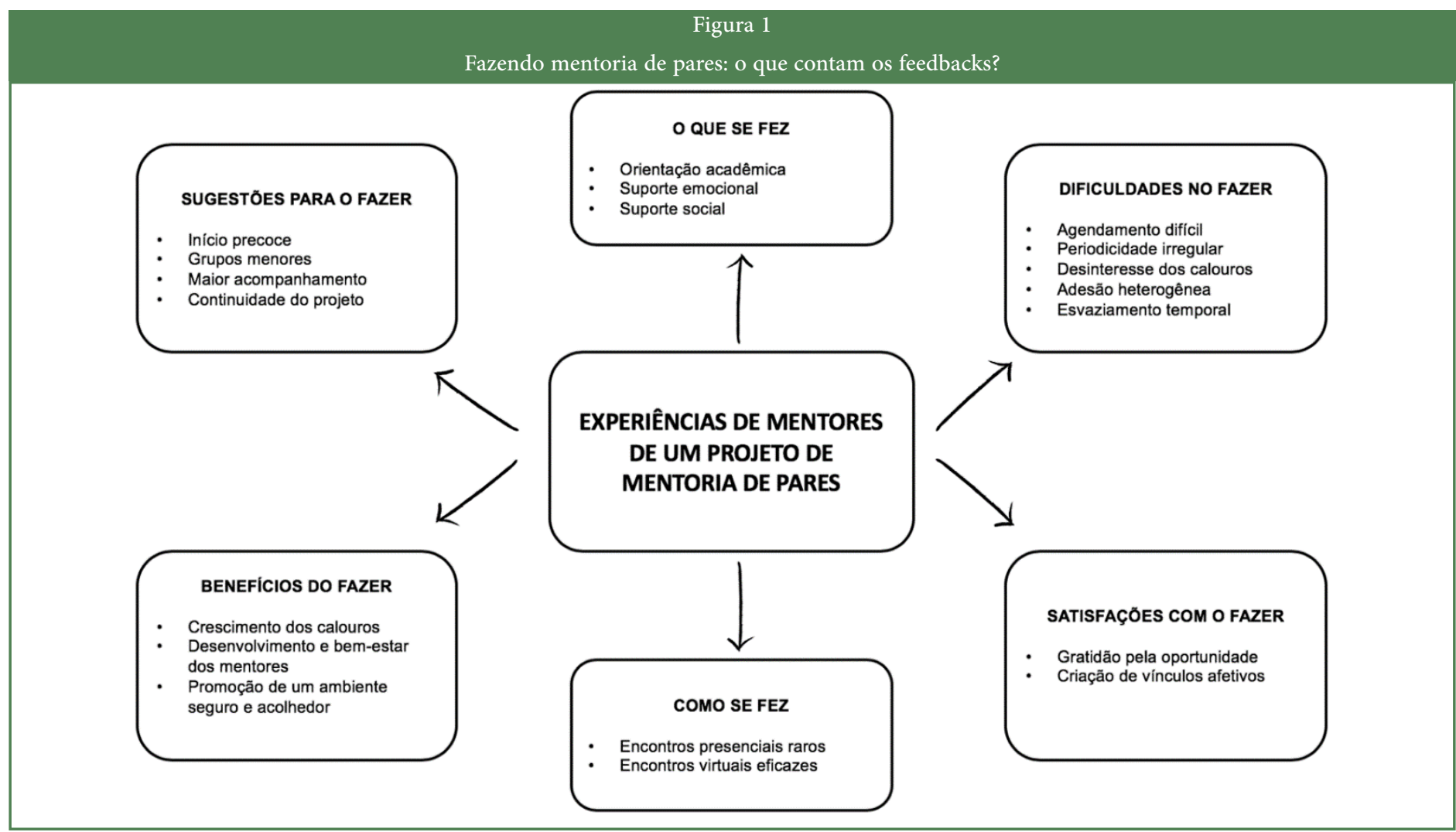

Fonte: Elaborada pelas autoras.

O que se fez

Orientação acadêmica

$\mathrm{Na}$ grande maioria dos feedbacks, os mentores relataram ações de suporte acadêmico, compartilhando resumos e materiais de estudo e aconselhando a como estudar e se organizar.

Já estou passando resumos e anotações, me ofereci para ficar no laboratório de anatomia com eles após as aulas. Quiseram saber um pouco de cada matéria e estou pensando em fazer um guia escrito para mandar para eles. Disponibilizei resumos e materiais para estudo para todos, de modo a buscarem confiança na vida acadêmica.

As primeiras provas foram temas de vários encontros, especialmente no final do primeiro semestre:

Assim que as provas começaram a chegar, passamos a fazer encontros basicamente para ajuda acadêmica: tirar dúvidas, trocar resumos e dicas etc. Em relação às provas, sempre me perguntam bastante coisa.

Suporte emocional

Os mentores também ofereceram apoio para o estresse derivado da transição. Muitas vezes ansiosos, os calouros puderam contar com o acolhimento e a empatia dos veteranos.

Eles reclamaram do cansaço e do excesso de informações que recebem de todos os lados, mas tranquilizei-os de que era normal no começo. Mando mensagens para cada um, perguntando como eles estão, se eu poderia ajudá-los de alguma forma.
Houve surtos pré-bioquímica e pré-anatomia! Nos momentos de desespero sempre me procuravam para saber se o que eles estavam fazendo estava certo.

Os mentores, lembrando-se de si mesmos quando novatos, muitas vezes reasseguraram aos calouros que as dificuldades seriam superadas.

Comentei que era uma fase de adaptação. Muitas vezes nosso desempenho não é bom nas provas, não porque não sabemos a matéria, mas porque estamos muito nervosos. Dei vários exemplos do que eu fazia no ano passado. Minha mentorada sempre me procura quando precisa desabafar sobre os problemas que enfrenta na faculdade: seja por nota, seja por crise de identidade (aquela mesma crise que todos nós bem conhecemos).

\section{Suporte social}

Os mentores funcionaram também como anfitriões, apresentando o ambiente acadêmico e as suas diferentes oportunidades.

As dúvidas foram de todos os âmbitos, inclusive em relação aos esportes e a como se organizar em meio a tantas atividades $e$ pensamentos na faculdade. Tentei focar no ambiente acadêmico: os treinos, os ensaios, as competições, os órgãos estudantis, todo o universo da faculdade que aparece de repente na nossa frente.

\section{Como se fez}

\section{Encontros presenciais raros}

Muitos mentores tiveram dificuldades em realizar os encontros presenciais mensais previstos pela coordenação do programa. 
Achei muito difícil fazer encontros pessoalmente porque os horários nunca batem. Comecei a ficar aflita por não conseguir marcar um horário para conversar com todos ao mesmo tempo e explicar como as coisas funcionavam.

\section{Encontros virtuais eficazes}

A grande maioria dos mentores buscou complementar os encontros presenciais com encontros à distância, via aplicativos de mensagens instantâneas, principalmente por áudio.

As calouras não decidiram uma data que desse para todas nessa semana. Conciliar os horários de todos era quase impossível $e$ uma boa forma de comunicação foi por WhatsApp mesmo. Pelo WhatsApp já pude tirar várias dúvidas delas do dia a dia, dos estudos, dos livros. Sempre mandava áudios imensos e tentava sanar todas as dúvidas. A gente conseguiu se encontrar algumas vezes, mas a comunicação é mais pelo grupo do WhatsApp mesmo.

\section{Dificuldades no fazer}

Agendamento difícil

Sem dúvida, uma das maiores dificuldades foi o agendamento dos encontros presenciais com o grupo.

O que foi realmente difícil no primeiro semestre foi conseguir marcar reuniões, todo mundo tem atividades bem diferentes, ficou complicado! Pelo fato dos calouros possuírem uma agenda disputadíssima, raras foram as vezes que pudemos nos encontrar todos. Por todos os horários de treinos e atividades, nunca consegui reunir todos juntos.

\section{Periodicidade irregular}

Os mentores também ficaram muito frustrados com a dificuldade em realizar encontros regulares.

Confesso que as reuniões mensais não saíram dos planos! Toda a correria dos treinos esportivos, das provas e compromissos pessoais tornou muito difícil concretizar nossos encontros! Só consegui fazer uma reunião com as minhas mentoradas. Foram tantas provas, minhas e delas, tantos compromissos... Isso me deixou tão triste.

Desinteresse dos calouros

Diferentes mentores relataram desinteresse dos calouros para os encontros, gerando frustração, decepção e sensação de impotência.

Fizemos apenas duas reuniões. Tentei marcar outras, mas elas não estão muito engajadas. Não sei mais o que fazer! Minhas mentoradas recorreram a mim pouquíssimas vezes. Elas não tinham muita disponibilidade para nossos encontros e me senti muito frustrada. Eu esperava ajudar mais. Infelizmente isso não foi possível por falta de tempo e por falta de procura delas também.

Alguns mentores relataram que a procura se deu apenas quando os calouros estavam em risco acadêmico:

Só um dos mentorados sempre me buscou, o resto só veio pedir ajuda quando estava com a corda no pescoço, precisando tirar muita nota no exame! Só foi me buscar numa época que achou que ia pegar exame de Bioquímica.

\section{Adesão heterogênea}

Para alguns mentores, foi difícil compreender as diferenças de interesse dentro do grupo.

Uma caloura me procura sempre, no sentido acadêmico. Outra conversa comigo sobre assuntos pessoais, somos próximas. A outra se mantém bem afastada. Não sei se ela não gosta de mim, se é extrema timidez ou se é o jeito dela mesmo. Pra mim o projeto deu certo com três calouras! A quarta só saiu do grupo sem falar nada e nunca mais falou comigo.

Esvaziamento temporal

Muitos mentores observaram um esvaziamento das demandas no segundo semestre.

No início eu senti que o projeto ajudou muito, nessa parte do
ano os calouros ficam super perdidos. No segundo semestre todos
já estavam bem adaptados e não precisavam mais de tanta
ajuda. Depois de um tempo me senti inútil como mentor. Por
outro lado, foi bom, os calouros aprenderam a caminhar por si
próprios; temos que aceitar essa "saída do ninho"!

Satisfações com o fazer

Gratidão pela oportunidade

Vários mentores iniciaram seus feedbacks desejando destacar, antes de tudo, gratidão pela oportunidade.

Eu queria mais uma vez agradecer aos coordenadores desse projeto maravilhoso! Estou honrada em estar fazendo parte disso! Obrigada de coração por terem confiado em mim. Gostaria de agradecer pela oportunidade de fazer parte desse lindo projeto. Se eu pudesse ter tido um mentor, as coisas poderiam ter sido bem mais fáceis. Por isso, gratidão por estar fazendo parte disso.

Criação de vínculos afetivos

A criação de vínculos afetivos foi muito satisfatória para os mentores, reconhecendo que a amizade iria perdurar para além da relação de mentoria.

Hoje eu não consigo mais vê-los como simples calouros. São, sim, meus amigos! O projeto criou em mim um vínculo e um carinho grande por eles! O ano vai acabar, mas esse sentimento não! Vou continuar sendo a pessoa que eles podem procurar a qualquer hora, como uma irmã mais velha, pois sabem que vou querer o melhor para eles.

Ter uma relação mais pessoal e singular com cada calouro também gerou muita satisfação.

Eu amei cada um deles, cada um do seu jeitinho, se descobrindo na faculdade a sua maneira! Estou amando ser mentora. Todos os meus cinco calouros são muito especiais, esforçados e legais. 


\section{Benefícios do fazer}

\section{Crescimento dos calouros}

Vários mentores observaram o crescimento e a capacidade dos calouros em superar as dificuldades ao longo do tempo:

Estou muito orgulhosa pelos meus calourinhos, eles passaram por muitas dificuldades, dúvidas e conseguiram superá-las. O que mais me surpreendeu nesse semestre foi ver o crescimento dos calouros diante dos meus olhos!

Desenvolvimento e bem-estar dos mentores

A mentoria também ajudou os mentores a se desenvolver e a vivenciar o curso de forma menos estressante.

Eu planejava mentorar meus calourinhos no dia a dia, mas, no final, acho que eles me mentoraram. É incrível a confiança que eles depositam em mim. Eles fazem de mim uma pessoa melhor. Para mim, o projeto está sendo algo essencial, que tem feito o segundo ano infernal algo mais tolerável. Sou extremamente grata!

Os veteranos puderam aprender sobre o papel de mentor, reconhecendo sua amplitude para além do âmbito acadêmico e do próprio grupo de mentoria.

Eu estava preparada para passar resumos, dicas de provas e de como se organizar na faculdade. No final, aprendi que ser mentora ultrapassa os limites das páginas de um caderno! Hoje eu tenho maior intimidade com outras pessoas dentro da turma, expandi a mentoria não somente aos que me escolheram!

Promoção de um ambiente seguro e acolhedor

Uma relação calouro-veterano baseada na confiança e sem outras demandas promoveu um ambiente seguro e acolhedor na faculdade.

Foi muito interessante os calouros poderem perguntar tudo para seus veteranos. Senti que construí uma família com as calouras. Além disso, é um espaço que tenho com elas independentemente dos outros órgãos estudantis. É um espaço em que elas podem ser sinceras comigo, e eu com elas, em todos os sentidos.

Sugestões para o fazer

Sugestões de mudança em alguns aspectos do programa e pedidos para a continuidade dele foram registrados nos feedbacks.

\section{Início precoce}

Como as necessidades dos calouros são maiores logo na chegada ao curso, vários mentores sugeriram fortemente que o programa inicie mais precocemente:

O início do ano é quando eles mais se sentem perdidos e precisam de conselhos. O ideal seria que o ano já começasse com os grupos divididos. Começar o projeto logo no primeiro dia! É o período que eles mais vão precisar.

\section{Grupos menores}

Considerando o desafio de uma data comum para as reuniões, alguns mentores recomendaram menor número de mentorados por grupo:
Talvez o número de calouros por mentor devesse ser um pouco menor também, no máximo três. Menos mentorados pra cada mentor, dois no máximo. É IMPOSSÍVEL conciliar todo mundo.

\section{Maior acompanhamento}

Mais reuniões com a coordenação do programa foram demandadas, tanto para maior orientação quanto para troca de experiências entre os mentores:

Os mentores ficaram muito jogados o ano inteiro pelos coordenadores, infelizmente. Acho que faltaram reuniões entre a organização e os mentores, para discutirmos mais e nos ajudarmos mais.

Continuidade do programa

Por fim, mas não menos importante, destacaram-se os pedidos enfáticos para que o programa continuasse nos próximos anos.

\footnotetext{
Que ele possa acontecer todos os anos para haver mais interação, empatia e acolhimento entre todos. Só queria agradecer e dizer para não deixarem esse programa maravilhoso acabar! Eu acredito MUITO no potencial de tudo isso, foi essencial para muitos calouros. Por favor, não deixem isso morrer!
}

\section{DISCUSSÃO}

Neste estudo trouxemos a experiência de alunos veteranos que, no papel de mentores, buscaram ajudar alunos calouros em seu processo de transição e adaptação ao curso médico. Como se deu esse fazer? Quais as satisfações encontradas? Quais os desafios enfrentados? Como aprimorar a experiência?

\section{O fazer na mentoria de pares}

Fazer mentoria de pares significou, para os nossos mentores, oferecer um suporte amplo à pessoa do calouro como um todo.

A orientação de aspectos acadêmicos esteve bastante presente nos encontros realizados. Os mentores compartilharam materiais de estudo e ajudaram os calouros a se organizar e estudar. Esse suporte parece ser bastante característico de programas de mentoria de pares. Alunos veteranos, por conta de suas experiências mais recentes, são considerados os mais bem posicionados para auxiliar nas preocupações cotidianas. Embora pareçam pequenas, questões como qual livro comprar ou quanto estudar podem impactar o dia a dia dos alunos e bem-estar geral deles ${ }^{20}$.

Muito importante também foi o papel de suporte dos mentores que tranquilizaram os calouros quanto à sua capacidade de enfrentar os desafios do curso. A dimensão psicossocial é também um importante elemento das relações de mentoria em geral. Um estudo recente investigou as percepções de calouros mentorados por veteranos, e, para os novatos, foi importante ter um mentor que não apenas sugerisse recursos apropriados, mas também os ajudasse a se desenvolver com menos ansiedade e estresse ${ }^{24}$. Outros estudos também concluem que os benefícios experimentados pelos alunos são derivados em grande parte do suporte psicossocial vivenciado na mentoria de pares ${ }^{19}$. Embora alunos de Medicina sejam tradicionalmente brilhantes e inteligentes, baixa autoestima e sofrimento emocional podem ocorrer no primeiro ano da escola médica. Veteranos, no papel de mentores, ao compartilharem os "truques do ofício", tornam os novos alunos mais confiantes e aumentam a resiliência deles ${ }^{22}$.

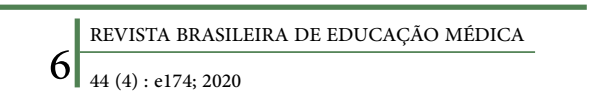


Muitos estudos mostram os alunos de Medicina com altos índices de ansiedade, depressão, burnout, e também maior sofrimento que alunos de outros cursos e que a população geral ${ }^{25}$. Estudos também referem que estudantes de Medicina preferem expressar suas necessidades emocionais entre seus pares mais do que em uma mentoria formal ${ }^{26}$. Um ambiente no qual as experiências possam ser abertamente discutidas entre colegas, como o proposto na mentoria de pares, pode então promover um importante fator protetor em saúde mental: a experiência de suporte social ${ }^{8,27}$. Mentores pares podem ajudar os alunos mais novos a se adaptar ao estilo de vida universitário e a se acalmar diante dos momentos difíceis $^{21,28}$. Por conta da congruência cognitiva e social, veteranos podem não só ajudar os calouros a entender melhor certos conceitos, como conseguem aliviar as ansiedades derivadas da transição ${ }^{29}$.

Destacou-se, no fazer dos mentores, o papel em ajudar os calouros a lidar com duas grandes fontes de estresse do primeiro ano do curso: o excesso de estímulos e as relações hierárquicas com os alunos mais velhos. Embora as diferentes atividades oferecidas no curso representem oportunidades de crescimento, seu volume excessivo deixa os calouros ansiosos e perdidos, sem saber em quem acreditar.

Nesse sentido, o desenvolvimento de uma relação de confiança foi um ponto forte em nosso programa. Diferentemente das tradicionais relações entre veteranos e calouros, marcadas, muitas vezes, por ações de intimidação, os calouros experimentaram um ambiente seguro e de cuidado. Em outras experiências, a mentoria de pares também reduziu essa fonte de estresse, a prática de trote, estimulando uma interação saudável entre os diferentes níveis da hierarquia acadêmica ${ }^{21}$.

\section{As dificuldades}

Fazer mentoria de pares nem sempre foi uma atividade de fácil realização. Vários mentores demonstraram dificuldade na promoção dos encontros presenciais tanto por conta do desafio do agendamento quanto pelo baixo engajamento de alguns calouros.

Tais dificuldades não são inéditas em programas de mentoria, sejam eles clássicos ou mentoria de pares, como o nosso. Revisões da literatura apontam a falta de tempo para o encontro como a maior barreira para a mentoria $^{15,16,22}$. A falta de iniciativa dos mentorados também tem sido descrita como preocupante ${ }^{21,30}$. Dificuldades logísticas decorrentes das agendas dos diferentes anos acadêmicos também prejudicam a regularidade dos encontros, um preditor importante dos benefícios da mentoria ${ }^{20,24}$.

Em nosso programa, por conta dessas dificuldades, as orientações aconteceram, muitas vezes, de forma virtual, via aplicativo de mensagens instantâneas. Não sabemos qual seria o balanço ideal entre encontros presenciais ou à distância, mas outros programas, diante dessas mesmas dificuldades e das características geracionais atuais, têm encorajado práticas de mentoria on-line $e^{19,21}$. Estudos posteriores poderão nos ajudar a compreender ainda se outras variáveis, como a personalidade ou a capacidade empática do mentor, influenciaram a realização maior ou menor dos diferentes tipos de encontro (presencial ou virtual).

\section{O efeito do tempo}

Segundo $\mathrm{Kram}^{31}$, a atividade de mentoria possui quatro fases: a iniciação, a cultivação, a separação, quando a natureza do relacionamento é alterada por mudanças estruturais ou psicológicas, e a redefinição, quando o relacionamento evolui para uma forma nova ou termina totalmente.
Em nosso programa, a separação pareceu ocorrer na segunda metade do ano, com diversos mentores relatando diminuição das demandas dos calouros. Fenômeno semelhante também ocorre em outros programas de mentoria. Por vezes, os encontros começam frequentes no início do programa e acabam reduzidos a encontros esporádicos no final ${ }^{19}$.

Muitos mentores observaram que o engajamento dos calouros na mentoria diminuiu com o aumento de sua adaptação ao ambiente acadêmico. Nesse sentido, vale considerar que a menor adesão à mentoria no segundo semestre talvez faça parte da natureza de um programa de mentoria desenvolvido com alunos ingressantes. Daloz ${ }^{32}$, importante autor no campo da mentoria, considera natural que um mentor, à medida que o mentorado se torna mais confiante e independente, tenha o seu papel mudado de guia para o de colega ou amigo. Essa mudança de papel foi observada em alguns feedbacks, com a relação caminhando, na segunda metade do ano, para a fase de redefinição.

\section{As satisfações}

Nosso estudo mostrou efeitos positivos da mentoria para os calouros e também para os próprios mentores. Muitos deles mostraram-se gratos pela oportunidade, reforçando estudos que destacam a mentoria como uma via de mão dupla ${ }^{14}$.

A mentoria de pares tem sido considerada uma ferramenta interessante para aprimorar uma série de habilidades nos alunos mais velhos, como habilidades de ensino, de liderança, comunicação e, especialmente, habilidades afetivas, como autoconfiança e paciência ${ }^{21,30}$. Destaca-se também a habilidade de autorreflexão, na medida em que, para ajudar os novatos, os mentores precisam refletir sobre as suas próprias experiências ${ }^{19}$.

Ser mentor tornou também mais gratificante a própria trajetória dos veteranos no curso, sendo a amizade dos calouros um suporte emocional para eles em seus momentos de dificuldade. Em programas semelhantes, mentores também relatam benefícios emocionais, sentindo-se felizes por saberem que são capazes de ajudar seus mentorados a conseguir caminhar bem ${ }^{21,30}$.

\section{Aprimoramentos}

Considerando-se as dificuldades enfrentadas, sugestões de aprimoramento foram feitas pelos mentores. Considerou-se importante que o programa, nas próximas edições, comece logo na chegada dos primeiros calouros, momento de maior necessidade deles. Sugeriram também que os grupos sejam menores, para facilitar o difícil agendamento dos encontros. Por fim, demandaram maior acompanhamento das atividades pela coordenação.

Sugestões como essas estão presentes em outros estudos, reconhecendo que melhores experiências de mentoria são decorrentes de maior e melhor preparação. Não há dúvida de que os mentores precisam receber treinamento inicial sobre os fundamentos da mentoria e que a coordenação dos programas deve estar disponível ao longo do tempo ${ }^{20,30,33}$. Nesse sentido, além da capacitação inicial, reuniões de acompanhamento mais frequentes, incentivando a troca de experiências entre os mentores, serão regularmente agendadas nas próximas edições do projeto.

\section{Limitações e forças}

Nosso estudo é derivado de experiência realizada em uma única escola médica, cujos resultados, nesse sentido, têm limitações, não permitindo a sua generalização. Contudo, muitos de nossos resultados confirmam

REVISTA BRASILEIRA DE EDUCAÇÃo MÉDICA

7 $74(4)$ : e174; 2020 
experiências similares em contextos diferentes do brasileiro, o que fortalece nossa investigação e a compreensão da essência da atividade de mentoria de pares. É importante destacar também que não temos conhecimento da descrição de outro programa similar na realidade brasileira.

Mesmo com essas limitações, acreditamos que nosso estudo colabora com o campo da mentoria de pares e gera perguntas importantes e interessantes, que pretendemos abordar em novos estudos:

- Será a percepção dos alunos congruente com a dos mentores?

- Serão os atuais mentorados também futuros mentores?

- Observaremos esse ciclo virtuoso nas próximas edições do programa?

\section{CONCLUSÕES}

Fazer mentoria de pares mostrou-se uma possível e satisfatória intervenção de suporte a ser promovida nas escolas médicas, no crítico momento da chegada dos novos alunos. É um fazer amplo, nos campos acadêmico e pessoal, que ajuda os alunos ingressantes a lidar com as incertezas e os excessos de estímulos presentes no início da jornada acadêmica.

A mentoria promove um espaço de confiança em que dúvidas e ansiedades podem ser compartilhadas. $\mathrm{O}$ desenvolvimento de relações de amizade ressignifica a relação calouro-veterano que passa a ser caracterizada pelo afeto e pela responsabilidade no crescimento do outro. A relação de mentoria mostra ser uma via de mão dupla, e o veterano, no papel de mentor, não só se desenvolve ao longo do processo, como também tem seu bem-estar no curso aumentado.

Dificuldades na realização dos encontros mostraram-se presentes, e aprimoramentos precisam ser realizados para que o engajamento com a mentoria permaneça ao longo do tempo e seus benefícios possam ser ampliados.

\section{AGRADECIMENTOS}

A todos os alunos mentores que participaram do estudo, agradecemos o tempo destinado ao programa e a abertura em compartilhar sua experiência.

\section{REFERENNCIAS}

1. Coulon A. O ofício de estudante: a entrada na vida universitária. Educ Pesqui. 2017;43(4): 1239-50.

2. Millan LR, Marco OLN, Rossi E, Arruda PV. O universo psicológico do futuro médico: vocação, vicissitudes e perspectivas. São Paulo: Casa do Psicólogo; 1999.

3. Millan LR, Marco OLN, Rossi E, Millan MPB, Arruda PV. Alguns aspectos psicológicos ligados à formação médica. Revista ABPAPAL. 1991;13(4):137-42.

4. Tanaka MM, Furlan LL, Branco LM, Valerio NI. Adaptação de alunos de Medicina em anos iniciais da formação. Rev Bras Educ Med. 2016;40(4):663-8.

5. Del-Ben CM, Machado VF, Madisson MM, Resende TL, Valério FP, Troncon LE. Relationship between academic performance and affective changes during the first year at medical school. Med Teach. 2013;35(5):404-10.

6. Wolf TM, von Almen TK, Faucett JM, Randall HM, Franklin FA. Psychosocial changes during the first year of medical school. Med
Educ. 1991;25(3):174-81.

7. Moffat KJ, McConnachie A, Ross S, Morrison JM. First year medical student stress and coping in a problem-based learning medical curriculum. Med Educ. 2004;38(5):482-91.

8. Kötter T, Tautphäus Y, Obst KU, Voltmer E, Scherer M. Healthpromoting factors in the freshman year of medical school: a longitudinal study. Med Educ. 2016;50(6):646-56.

9. Heinen I, Bullinger M KR. Perceived stress in first year medical students associations with personal resources and emotional distress. BMC Med Educ. 2017;17(1).

10. Bellodi PL. O Programa Tutores e a integração dos calouros na FMUSP. Rev Bras Educ Med. 2004;28(3):204-14.

11. Bellodi PL, Martins MA e colaboradores. Tutoria: mentoring na formação médica. São Paulo: Casa do Psicólogo; 2005.

12. Standing Committee on Postgraduate Medical and Dental Education. An enquiry into mentoring. A SCOPME report. London: Department of Health, 1998.

13. Stenfors-Hayes T, Kalén S, Hult $H$, Dahlgren LO, Hindbeck $H$, Ponzer S. Being a mentor for undergraduate medical students enhances personal and professional development. Med Teach. 2010;32(2):148-53.

14. Crisp G, Cruz I. Mentoring college students: a critical review of the literature between 1990 and 2007. Res High Educ. 2009;50:525-45.

15. Frei E, Stamm M, Buddeberg-Fischer B. Mentoring programs for medical students-a review of the PubMed literature 2000-2008. BMC Med Educ. 2010;10(32).

16. Buddeberg-Fischer B, Herta KD. Formal mentoring programmes for medical students and doctors - a review of the Medline literature. Med Teach. 2006;28(3):248-57.

17. Lareau S, Blumstein H, Hopson L, Keller BL, Haydel MJ, Cheaito MA, et al. Selecting a Medical School Advisor. J Emerg Med. 2019;56(5):e91-e93.

18. Steele MM, Fisman S, Davidson B. Mentoring and role models in recruitment and retention: a study of junior medical faculty perceptions. Med Teach. 2013;35(5):e1130-8.

19. Abdolalizadeh P, Pourhassan S, Gandomkar R, Heidari F, Sohrabpour AA. Dual peer mentoring program: exploring the perceptions of mentors and mentees. Med J Islam Repub Iran. 2017;31(1).

20. Andre C, Deerin J, Leykum L. Students helping students: vertical peer mentoring to enhance the medical school experience. BMC Res Notes. 2017;10(1):1-7.

21. Singh S, Singh N, Dhaliwal U. Near-peer mentoring to complement faculty mentoring of first-year medical students in India. J Educ Eval Heal Prof. 2014;11(12).

22. Akinla O, Hagan P, Atiomo W. A systematic review of the literature describing the outcomes of near-peer mentoring programs for first year medical students. BMC Med Educ. 2018;18(98).

23. Bardin L. Análise de conteúdo. São Paulo: Edições 70; 2011.

24. Altonji SJ, Baños JH, Harada CN. Perceived benefits of a peer mentoring program for first-year medical students. Teach Learn Med. 2019;31(4):445-52.

25. Dyrbye LN, Thomas MR, Shanafelt TD. Systematic review of depression, anxiety, and other indicators of psychological distress among U.S. and Canadian medical students. Acad Med. 


\section{6;81(4):354-73.}

26. Vries-Erich JM, Dornan T, Boerboom TBB, Jaarsma ADC, Helmich E. Dealing with emotions: medical undergraduates' preferences in sharing their experiences. Med Educ. 2016;50(8):817-28.

27. Dyrbye LN, Power DV, Massie FS, Eacker A, Harper W, Thomas MR, et al. Factors associated with resilience to and recovery from burnout: a prospective, multi-institutional study of US medical students. Med Educ. 2010;44(10):1016-26.

28. Yusoff MSB, Abdul Rahim AF, Noor AR, Yaacob NA, Mohd Hussin ZA. Evaluation of medical students' perception towards the BigSib programme in the School of Medical Sciences, Universiti Sains Malaysia. Educ Med J. 2010;2(1):2-11.

29. Taylor JS, Faghri S, Aggarwal N, Zeller K, Dollase R, Reis SP. Developing a peer-mentor program for medical students. Teach Learn Med. 2013;25(1):97-102.

30. McLean M. Does the curriculum matter in peer mentoring? From mentee to mentor in problem-based learning: a unique case study. Mentoring \& Tutoring: Partnership in Learning. 2004;12(2):173-86.

31. Kram KE. Phases of the mentor relationship. Acad Manage J. 1983;26(4):608-25.

32. Daloz LA. Effective teaching and mentoring: realizing the transformational power of adult learning experiences. San Francisco: Jossey-Bass; 1986.
33. Chatterton E, AnisF, Atiomo W, Hagan P. Peer mentor schemes in medical school: their need, their value and training for peer mentors. Stud High Educ J. 2018;2(2):47-60.

\section{CONTRIBUIÇÃO DAS AUTORAS}

Marina Guitti de Souza projetou o estudo e realizou a coleta e análise de dados. Lígia de Fátima Nóbrega Reato colaborou nos procedimentos para a aprovação do estudo pelo Comitê de Ética da FMABC e na análise dos dados. Patrícia Lacerda Bellodi orientou o desenho do estudo e colaborou na análise e interpretação dos dados. Marina Guitti de Souza e Patrícia Lacerda Bellodi redigiram o manuscrito. Todas as autoras aprovaram a versão final.

\section{CONFLITO DE INTERESSES}

As autoras declaram não haver conflito de interesses neste estudo.

\section{ENDEREÇO PARA CORRESPONDÊNCIA}

Marina Guitti de Souza. Rua Vicente Porto, 648, Barão Geraldo, Campinas, SP, Brasil. CEP: 13085-080.

E-mail: marinaguittis@hotmail.com 